\title{
Thieves or mutualists? Pulp feeders enhance endozoochore local recruitment
}

\author{
José M. Fedriani, ${ }^{1,3}$ Magdalena Zywiec, ${ }^{2}$ and Miguel Delibes ${ }^{1}$ \\ ${ }^{1}$ Estación Biológica de Doñana (CSIC), Avda. Américo Vespucio s/n, Isla de la Cartuja, 41092 Sevilla, Spain \\ ${ }^{2}$ Polish Academy of Sciences, Institute of Botany, ul. Lubicz 46, 31512 Krakow, Poland
}

\begin{abstract}
The persistence of mutualisms despite the strong incidence of exploiters could be explained if exploiters deny one or more services (i.e., cheat) while eventually supplying some subtler but critical services. Pulp feeders usually ingest fruit reward without dispersing seeds and thus are considered to be mainly cheaters or thieves of seed-disperser mutualisms. By consuming the fruit pulp, however, they could release seeds from pulp inhibitory effect, enhancing germination and, potentially, subsequent seedling emergence, growth, survival, and thus local recruitment. We evaluated such a largely neglected hypothesis by considering the interaction between Pyrus bourgaeana and its pulp feeders. We experimentally showed that pericarp removal had a consistent strong positive effect on seed performance (e.g., lower rotting and higher germination percentages) and seedling fate (greater emergence, growth, and survival to two years old). Interestingly, these relatively large positive effects of depulpation on plant fitness persisted for a surprisingly long time. Though seedlings experienced higher mortality under fruiting conspecifics, the benefits of depulpation were not overridden by high propagule mortality beneath fruiting trees or in adverse microhabitats after two years of monitoring. Specifically, the cumulative probability of establishment for depulped seeds was 4-25 times higher than for seeds in whole ripe fruits. Thus, under some circumstances, pulp feeders can provide essential services to endozoochorous plants. Our study contributes to clarifying the apparent paradox of plant-frugivore mutualisms that persist in the face of exploitation by pulp feeders. Because "thieves" and "mutualists" refer to the extremes of a complex continuum, and because organisms displaying concurrent cheating and honest behaviors during different host stages are likely prevalent, the persistent language of mutualists vs. thieves, cheaters, or exploiters might be misleading.
\end{abstract}

Key words: cheaters; Doñana National Park, Spain; functional uniqueness; germination inhibition; invertebrate seed predation; mediterranean ecosystem; mutualism stability; Pyrus bourgaeana; recruitment; seed dispersal; seedling growth and survival; selective defaunation.

\section{INTRODUCTION}

Interactions between plants and their mutualistic animal partners are central to the ecology and evolution of most plant lineages and are at the core of essential ecosystem services (pollination, seed dispersal, and so forth; Thompson 2005, Bronstein et al. 2006, Herrera 2009). Typically, a plant species offers its animal mutualistic partners commodities that are relatively inexpensive for it to produce (e.g., nectar, fruit pulp) in exchange for services that are more expensive or unfeasible (e.g., antiherbivore defense, propagule movement). Interestingly, this "biological market" also comprises organisms that exploit plant rewards, apparently without reciprocating, which have been branded with myriad unflattering names such as exploiters, cheaters, or thieves (e.g., Howe 1977, Wheelwright and Orians 1982, Bronstein 2001, Irwin et al. 2010). This has

Manuscript received 5 March 2011; revised 11 August 2011; accepted 1 September 2011. Corresponding Editor: R. T. Corlett.

${ }^{3}$ E-mail: fedriani@ebd.csic.es lead to frequent linguistic conventions, such as mutualists vs. exploiters, that, despite their heuristic value, merely identify the extremes of a more complex continuum. Indeed, though exploiters impose costs (e.g., damage to the plant reproductive organs or propagules), their net effect on plant fitness is not necessarily negative and thus becomes difficult to forecast (Maloof and Inouye 2000, Yu 2001, Irwin et al. 2010). One overlooked explanation of the apparent paradox of mutualism persistence in the face of exploitation is that exploiters deny plant hosts of one or more services at certain stages, while eventually supplying some subtler but critical services (see Palmer et al. 2010). Consequently, an inclusive evaluation of fitness costs and benefits imposed by putative exploiters along different stages of the plant life cycle and recruitment process could be decisive to understanding their role in plant-animal mutualisms.

Many vertebrate-dispersed plants have evolved edible seed coverings or appendages to attract frugivores. Large-sized vertebrates frequently ingest the package made up of seeds plus the rewarding flesh, transport the 
seeds internally (i.e., endozoochory), and often release them away from the parental environment, where survival may be higher (i.e., legitimate dispersal). Small-sized birds and mammals, however, are thought to cheat on fleshy-fruited plants by ingesting the fruit pulp without dispersing seeds, leaving them within the risky parental environment and lessening dispersal by legitimate dispersers (e.g., Howe 1977, Herrera 1981, Wheelwright and Orians 1982, Snow and Snow 1988, Tewksbury et al. 2008, Olesen et al. 2010). Nonetheless, by consuming part or most of the fruit pulp, such pulp thieves (sensu Howe 1977) could release seeds from the pericarp inhibitory effect (Robertson et al. 2006), enhancing germination and, presumably, other plant stages such as seedling survival. Even though there has been commendable research effort on fruit-frugivore interactions (see Levey et al. [2002], Dennis et al. [2007], and Jordano et al. [2010] reviews), the role of pulp feeders on endozoochore recruitment remains unclear (Loayza and Knight 2010).

Earlier research on the effects of pulp feeders on plant fitness (reviewed in Kelly et al. 2004, Samuels and Levey 2005, Robertson et al. 2006, Traveset et al. 2007) shows several flaws that might have stimulated the assumption that they mostly act as thieves of seed-disperser mutualisms. First, the effects of pulp consumption are likely to be contingent on the environmental setting (laboratory, glasshouse, field) and, surprisingly, seldom have been assessed under realistic field conditions (Robertson et al. 2006). Second, available assays have focused on how fruit pulp impinges the probability and speed of germination, overlooking the possibility that changes in germination behavior influence other subsequent processes at later plant life stages (e.g., emergence, seedling growth, survival). In particular, delayed germination can impart fitness costs, such as overexposure to seed pathogens and reduced seedling survival (Curran and Web 2000, Daws et al. 2005, Verdú and Traveset 2005). Third, fruit pulp may provide adaptive functions other than inhibition of germination until dispersal (e.g., the protection of seeds from pathogens; Cipollini and Levey 1997, Fragoso et al. 2003), which can lead to effects acting in opposite directions; however, such potential trade-offs in plant fitness have been rarely considered. Lastly but importantly, because of high seed and seedling mortalities beneath fruiting conspecifics (e.g., Howe 1980, Augspurger 1984, Fragoso et al. 2003, Fenner and Thompson 2005), it is sometimes assumed that the potential fitness benefits of pulp removal are offset by low propagule survival beneath mother plants. Consequently, accounting for potential conflicting effects of pulp consumption at different plant stages under field conditions, as well as estimating the likelihood of recruitment under fruiting conspecifics, is required to fully understand the effects of pulp feeders on plant recruitment.

In this study we assess fitness costs and benefits experienced by the endozoochorous Iberian pear Pyrus bourgaeana at different ontogenic stages in its interaction with pulp feeders. In southwestern Spain, abundant small mammals (mostly rabbits, Oryctolagus cuniculus) apparently act as pulp thieves of $P$. bourgaeana fruits, frequently leaving partially consumed fruits with uneaten seeds underneath fruiting trees (Fedriani and Delibes 2009a). Medium-sized mammalian carnivores such as badgers (Meles meles) and red foxes (Vulpes vulpes) are the local legitimate dispersers of $P$. bourgaeana, though they infrequently visit fruiting trees. Thus a fraction of fruit crops is undispersed and left partially eaten or whole under fruiting trees (Fedriani and Delibes 2009a), which usually are considered to be unlikely to recruit. Nevertheless, an inclusive evaluation of the fate of nondispersed seeds within fruits handled by pulp feeders or within whole fruits is lacking for most study systems, including ours.

To evaluate the largely neglected hypothesis that links pulp feeders to plant establishment, we used a simple stage-structured model of plant recruitment beginning with mature seeds and examining the transition probabilities to subsequent life stages (seed germination, seedling emergence, growth, survival; Rey and Alcántara 2000, Balcomb and Chapman 2003, Vilà et al. 2006). Using this framework and a field-sowing experiment, we compared the fate of P. bourgaeana seeds and seedlings under contrasting pulp treatments (i.e., depulped and nondepulped seeds) and also evaluated the spatial consistency of propagule fate. Because fungal pathogens and chemical allelopathy are often associated with fruiting conspecifics (e.g., Fenner and Thompson 2005), possible fitness benefits of depulpation could be offset as a consequence of high mortality beneath fruiting trees. Additionally, since in arid and semiarid ecosystems (e.g., those of the Mediterranean basin) abiotic conditions in uncovered microsites are often harsh (Maestre et al. 2005, Pugnaire and Valladares 2007), we evaluated whether the presumed benefits of depulpation were contingent on the microhabitat where fruits fall. Specifically, our experimental approach aimed to answer four questions. (1) Does pulp removal enhance different components (germination, emergence, survival) of $P$. bourgaeana fitness? (2) If so, are the presumed benefits of depulpation overridden by severe propagule mortality under fruiting conspecifics? (3) Are the effects of pulp removal consistent across microhabitats? (4) What is the net effect of pulp removal on seedling establishment?

\section{Study Area and Species}

Our study area was located in the Doñana National Park $\left(510 \mathrm{~km}^{2} ; 37^{\circ} 9^{\prime} \mathrm{N}, 6^{\circ} 26^{\prime} \mathrm{W}\right.$; elevation $\left.0-80 \mathrm{~m}\right)$, on the west bank of the Guadalquivir River estuary in southwestern Spain. Pyrus bourgaeana Decne (Rosaceae) is a close relative of the domestic pear Pyrus communis L. distributed across the southern Iberian Peninsula and northern Morocco (Aldasoro et al. 1996). In the Doñana area, the distribution of this monoecious 
small tree (typically 3-6 m high) is very fragmented, with trees occurring at low densities (generally $<1$ individual/ ha) in several patches of mediterranean scrubland that are isolated from each other by towns, cultivations, marshes, or sand dunes (Fedriani et al. 2010, Fedriani and Delibes 2011). Within these patches, the mature trees are strongly aggregated in small clusters (8-10 individuals within a radius of $\sim 25 \mathrm{~m}$; Fedriani et al. 2010). Our focal $P$. bourgaeana population occurred within a mediterranean shrubland dominated by Pistacia lenticus shrubs (14.5\% ground cover) growing singly or in small clumps and separated by either mostly unvegetated space with some annual herbs $(68.8 \%$ of total area) or a sparse understory of up to nine shrub species (e.g., Chamaerops humilis, Halimium halimifolium, Ulex spp., Cistus spp.; Fedriani and Delibes 2009a). Quercus suber, Olea europaea var. sylvestris, and Fraxinus angustifolia trees are scattered across the site. The climate is mediterranean subhumid, characterized by dry, hot summers (June-September) and mild, wet winters (November-February). Annual rainfall varies widely, ranging during the last 25 years from 170 to $1028 \mathrm{~mm}(583.0 \pm 221.1 \mathrm{~mm}$, mean $\pm \mathrm{SD})$. Though most rain $(\sim 80 \%)$ falls between October and March, there is a marked interannual seasonal variability in rainfall.

In Doñana, P. bourgaeana flowers from February to March, with each individual producing 200-450 fruits that ripen and drop to the ground unaided from September to December (Fedriani and Delibes 2009a). These fruits are adapted to mammal dispersal (Jordano 1995, Fedriani and Delibes 2009a). Fruits are nondehiscent globose pomes (2-3 cm diameter; Appendix A) weighing $\sim 6.7 \mathrm{~g}$, with a sugary water-rich pulp, and have a high pericarp : seed mass ratio $(26.6 \pm 3.8, n=70$; J. M. Fedriani, M. Zywiec, and M. Delibes, unpublished data). The pericarp comprises three layers, from outer to inner: (1) a green to brownish papery exocarp; (2) a fleshy, well-developed mesocarp loaded with lignified stone cells; and (3) a cartilaginous endocarp (core) where seeds are tightly implanted. In our study area, each fruit usually contains three full seeds $(73.5 \pm 22.2 \mathrm{mg}$ each) plus a variable number (4-6) of empty aborted seeds (Fedriani and Delibes 2009b). Predispersal seed losses by invertebrates (microlepidoptera larvae) are usually low (<3\%; Fedriani and Delibes 2009a). Pyrus seeds contain cyanogenic glycosides that are toxic for rabbits and other wildlife (Eisler 1991). Seeds germinate epigeally either shortly after dispersal, or even within fallen fruits, and do not appear to persist in the soil seed bank (Fedriani and Delibes 2009b). Seedlings emerge from winter to early spring, and extensive mortality occurs on young seedlings due to summer droughts and fungal infection, even though some of them resprout after the first fall rains (Fedriani and Delibes 2009b).

The abundant rabbits and some rodents (mostly Apodemus sylvaticus and Mus spretus) are the main $P$. bourgaeana fruit feeders (35.5-45.5\% of fallen fruits), gnawing them along their longitudinal axis, eating part of the fruit pericarp (Appendix A), and frequently leaving the discarded fruit halves with uneaten seeds $(1.8 \pm 0.9$ seeds per fruit, $n=130)$ under fruiting trees (Fedriani and Delibes 2009a; J. M. Fedriani, M. Zywiec, and M. Delibes, unpublished data). Pulp-feeding birds also drop some partially eaten fruits and clean seeds under fruiting trees. The relatively abundant ungulates (red deer Cervus elaphus and wild boar Sus scrofa) generally ingest whole fallen fruits (21.5-23.5\%) but grind ingested seeds and mostly act as seed predators. Finally, badgers and foxes remove only a small fraction (1.5-3.0\%) of whole fruits fallen to the ground (J. M. Fedriani, M. Zywiec, and M. Delibes, unpublished data), dispersing ingested seeds away from conspecifics with the capacity of germination (Fedriani and Delibes 2009a, b; Fedriani et al. 2010). These dispersers, however, have declined to low densities by illegal hunting and other human activities (Revilla et al. 2001, Fedriani et al. 2010, Fedriani and Delibes 2011). Fruit-removal field experiments in Doñana (e.g., Fedriani and Delibes 2009a) indicate that the likelihood of removal by legitimate dispersers of $P$. bourgaeana fruits partially eaten by pulp feeders is only about $60 \%$ as high as that for whole ripe fruits (J. M. Fedriani, M. Zywiec, and M. Delibes, unpublished data). Thus many partially eaten fruits remain beneath fruiting trees at the end of the dispersal season (Appendix A). Dust and soil brought by water runoff during winter storms often bury undispersed fruits to variable extent, and seedlings emerging from them are occasionally found (Appendix A).

\section{Methods}

Throughout this manuscript, we define "pulp feeders" as foragers that usually feed on fruit pericarp and discard some or all seeds within partly eaten fruits (in Doñana, mostly rabbits but also some birds and rodents; Fedriani and Delibes 2009a). "Seed predators" refers to large frugivores (i.e., ungulates) that typically ingest whole fruits and grind seeds into tiny pieces. "Legitimate dispersers" refers to frugivores (i.e., the badger and fox) that usually ingest whole fruits and release viable seeds away from conspecifics. Nonetheless, there are no clearcut limits in such classifications (Traveset 1994); for example, Pyrus bourgaeana pulp feeders occasionally move some handled fruits a few meters away from fruiting trees, and all fruit eaters drop some clean seeds during fruit handling and processing. Rodents also act as predators of seeds dispersed by carnivores, and carnivores destroy some seeds during ingestion and digestion (see Fedriani and Delibes 2009a).

\section{Experimental field sowing}

We simulated the effect of pulp feeders by handremoving part of the pericarp from some fruits (e.g., Silvius and Fragoso 2002, Fragoso et al. 2003, Robertson et al. 2006) and compared seed and seedling fate under different pericarp treatments. Specifically, we 
considered the following three pericarp treatments: (1) intact pericarps (seeds within whole ripe fruits) that would correspond with fallen fruits that remain uneaten on the ground at the end of the dispersal season, (2) partially depulped pericarps (seeds within fruit halves) that would correspond to fruits partially eaten by pulp feeders, and (3) hand-cleaned seeds that would correspond to seeds dropped or spat out by pulp feeders during fruit handling and processing. Because we focused on the effects of the abundant pulp feeders on tree recruitment, scarified seeds delivered by the infrequent legitimate dispersers were not considered (but see Fedriani and Delibes [2009b]).

Our field seed-sowing experiment, set up in October 2008 , accounted for the combined effect of pericarp removal, distance from fruiting conspecific, and microhabitat on P. bourgaeana seed and seedling fate. We haphazardly chose 15 fruiting trees (i.e., experimental blocks), all of which had the area beneath their crowns occupied by Pistacia and unvegetated space (a locally recurrent circumstance; Fedriani and Delibes 2009a). Spacing between adjacent blocks was $\sim 40 \mathrm{~m}$. For the experiment we used a $3 \times 2 \times 2$ randomized complete block design whose factors were pericarp removal (whole fruits, partially depulped fruits, and clean seeds), distance from fruiting conspecific (beneath and away [i.e., $\sim 15 \mathrm{~m}$ ] from fruiting trees), and microsite (under a Pistacia shrub or in an open microsite). These two kinds of microsite were chosen because they clearly predominate in our study site, together comprising $83.3 \%$ of the area. Thus in each block, we used all 12 possible combinations of experimental treatments.

In each block, we used three seed depots (one per pericarp-removal treatment) within each type of distance $\times$ microhabitat combination. Overall this generated 180 depots: 15 blocks $\times 2$ distances $\times 2$ microhabitats $\times 3$ pericarp treatments. Each seed depot consisted of an open-bottomed plastic beaker ( $7 \mathrm{~cm}$ diameter) pushed partially into the ground (Robertson et al. 2006, Fedriani and Delibes 2009b, Fedriani and Delibes 2011). For the whole-fruit treatment, three whole, ripe pears were placed in the depot. Because pulp feeders usually eat one-half of a fruit pericarp (Appendix A), we mimicked such partial depulpation by using six similar-sized pear halves for the partially depulped treatment. Fruits were split using a round-tip knife, and much care was paid to avoid damaging or displacing the seeds. Seeds within simulated eaten fruits thus remained partially contained within the pericarp. For the cleaned-seed treatment, nine viable hand-depulped seeds were sown per depot, given that fruits typically contain three seeds and we attempted to sow similar seed numbers per depot. Experimental fruits were collected two days before sowing from ripe crops of 11 neighboring individuals and were pooled prior to treatment assignments. Fruits infected by invertebrates, aborted, or shriveled were discarded. To avoid potential bias due to fruit preference by foragers, we did not use fruits that had been handled by pulp feeders. Beakers prevented the soil carried by water runoff to enter and bury sown seeds during winter storms; thus to resemble natural circumstances, we shallowly ( $\sim 5 \mathrm{~mm}$ depth) covered them using in situ soil previously sieved to remove nonexperimental seeds (Fedriani and Delibes 2009b, Fedriani and Delibes 2011). Previous assays indicated clearly that contamination by nonexperimental $P$. bourgaeana seeds did not occur under our protocol (Fedriani and Delibes 2009b), which was supported during this study by lack of conspecific seeds and seedlings associated with our depots. To prevent frugivores from altering target pericarp treatments, and to avoid trapping by ungulates, all depots were covered with a $1-\mathrm{cm}$ mesh cage $(28 \times 18 \times$ $13 \mathrm{~cm}$; Fedriani and Delibes 2009b). We monitored seedling emergence and survival monthly from November 2008 to June 2010. Ball-headed colored pins were placed next to each emerged seedling upon each check, allowing us to distinguish among monthly seedling cohorts. Most seedling mortalities $(95.7 \%, n=395)$ took place during the first 10 months (i.e., until August 2009); thus seedling survival up to the end of this study ( 20 months after seed sowing) was considered a valid proxy of establishment.

\section{Seed fate}

At the end of the study (June 2010), we estimated seed fate by retrieving experimental seeds from all 15 blocks. Overall, we retrieved remains of 1275 seeds, which were categorized as germinated, rotted, or depredated by invertebrates. Germination takes place from the proximal base of the seed, with the testa splitting along its longitudinal axis into halves. Numerous split testas within whole and partially depulped fruit were often found, indicating that $P$. bourgaeana seeds have the potential to germinate within intact fruits. Seeds attacked by invertebrates usually showed a single hole on one side and were largely empty. Since we had excluded visibly predated fruits, and because predispersal seed predation on the source trees was low during our study $(2.6 \% \pm 1.3 \%, n=60$ fruits; J. M. Fedriani, M. Zywiec, and M. Delibes, unpublished data), we assumed that our estimates of seed predation by invertebrates during the sowing were, at most, slightly overestimated. Seeds that did not germinate nor were depredated $(n=$ 358) were often externally discolored. After carefully removing their testas using forceps, we found that the remaining internal tissues were decayed due to infection by microbial pathogens. Therefore, no viability tests (e.g., Tetrazolium; Fedriani and Delibes 2011) were needed.

\section{Transition probabilities}

We integrated our results by calculating several transition probabilities (TP) and the cumulative probability of P. bourgaeana seedling establishment (CPE) from seed sowing to seedling establishment on a pertreatment basis. Transition probabilities were calculated 
as the ratio of the number of individuals completing a stage over the number of individuals entering that same stage (e.g., Rey and Alcántara 2000, Balcomb and Chapman 2003, Vilà et al. 2006). Specifically, we calculated the following TPs: (1) seed germination (number of seeds that germinated over the number of sown seeds), (2) seedling emergence (number of germinants that emerged as seedlings over the number of germinated seeds), and (3) seedling survival (number of alive seedlings at the end of the study over the number of emerged seedlings). We did not show a specific transition probability for seed survival (proportion of surviving seeds either germinated or not) because it equaled to seed germination, given that all nongerminated seeds had died by the end of the study. We then calculated the cumulative probability of seedling establishment as the product of all stage-specific transition probabilities (Fig. $3)$. Though this estimate is far from representing the lifetime fitness of the plant, it does show effects through germination and establishment, which are the most hazardous stages of plant regeneration (Alcántara and Rey 2003), and after two years, any ongoing effects of pulp treatment should be minimal (though seedling location will likely influence seedling performance beyond two years). Interpretation of TPs requires the consideration of some limitations of our sampling procedure. To prevent interferences of the germination and emergence processes, seed fate was assessed at the conclusion of the study, and thus we missed the chronological order of some events (e.g., seed-rotting events could have initiated before and/or after seed germination). Whatever the chronological order, however, it did not alter our estimates of transition probabilities nor the cumulative probability of establishment. Though sample sizes were generally acceptable, few seedlings emerged from whole fruits and, thus some TPs for that treatment (next to dashed arrows in Fig. 3) must be considered with caution. Finally, since in the study area there are a myriad of microsites (open interspaces and up to 10 shrub species; Fedriani and Delibes 2009b), it was not feasible to account for all possible microsites in our field experiment. Hence, we focused on the two most representative microsites and applied a randomized complete block design that allowed for rigorous comparisons of TPs and CPEs under different treatment combinations.

\section{Statistical analyses}

Data on percentages of $P$. bourgaeana seed germination, seedling emergence, seedling size, and survival were analyzed fitting generalized linear mixed models using Proc Glimmix in SAS (Littell et al. 2006). The effects of pericarp removal, distance from fruiting conspecifics, microhabitat, as well as their second- and third-order interactions were specified in the models as fixed effects, whereas the experimental block was included as a random factor. A significant interaction between peri- carp removal and any other fixed factor would indicate spatial inconsistency in its effect. For count (number of leaves) and proportion (e.g., seedling emergence and survival) response variables, we specified in the models the appropriate error (Poisson and binomial, respectively) and the canonical link function (see Littell et al. 2006). To compare the effects of different levels of any significant main factor, we calculated the differences between their least-square means. When the interaction between any two factors was significant, we performed tests for the effect of a given factor at the different levels of the other factor (tests of simple main effects), using the SLICE option in the LSMEANS statement of the MIXED procedure (Littell et al. 2006).

To evaluate the potential effects of target factors on the speed of $P$. bourgaeana seedling emergence and on seedling survivorship, we used failure-time analyses by fitting Cox proportional hazard regression models (e.g., Santamaría et al. 2002, Fedriani and Delibes 2011). In analyzing the speed of seedling emergence, data consisted of the number of months between sowing and seedling emergence, and since all nongerminated seeds were dead by the end of the study, they were modeled as noncensored. For seedling survivorship, however, the response variable was the number of months between seedling emergence and death and was modeled as rightcensored due to the uncertainty that these seedlings could eventually die after our study. In both analyses, the effect of experimental block was accounted for by including it into the models as a "frailty" (i.e., random) term. The significance of each factor and interaction was evaluated by backward-stepwise elimination from the full model (Therneau and Grambsch 2000). In comparing successive models, we calculated the double absolute difference of their respective expectation-maximization (EM) likelihood algorithms, and compared that value against a chi-square with $k-1$ degrees of freedom, $k$ being the number of levels (or combination of levels) of the factor (or interaction) being tested. For the frailty factor we also assumed a chi-square distribution with one degree of freedom (Therneau and Grambsch 2000).

\section{ReSUlts \\ Seed fate}

Almost a third of sowed Pyrus bourgaeana seeds (411 out of 1340) had rotted by the end of the experiment. Once the block effect was corrected for, our mixed model revealed that pericarp removal had a strong significant effect on the likelihood of rotting (Table 1). As predicted, the percentage of rotted seeds was 1.8 times higher for seeds in whole fruits as compared with that for partially depulped fruits. The incidence of rotting was threefold and 1.9-fold higher for seeds in whole and partially depulped fruits, respectively, compared to clean seeds (Fig, 1A). Additionally, seed rotting was significantly more frequent in open microsites $(37.7 \% \pm 6.0 \%)$ than under Pistacia shrubs $(23.5 \% \pm$ $5.9 \%$; Table 1). No other factor or interaction was found 
TABLE 1. Main results of the general linear mixed models ( $F$ values) in a study of the Iberian pear Pyrus bourgaeana in Doñana National Park, southwestern Spain.

\begin{tabular}{|c|c|c|c|c|c|c|c|c|c|c|c|c|}
\hline \multirow[b]{2}{*}{ Factor } & \multicolumn{3}{|c|}{ Seed rotting } & \multicolumn{3}{|c|}{ Seed predation } & \multicolumn{3}{|c|}{ Seed germination } & \multicolumn{3}{|c|}{ Seedling emergence } \\
\hline & df & $F$ & $P$ & df & $F$ & $P$ & df & $F$ & $P$ & df & $F$ & $P$ \\
\hline Pericarp removal $(\mathrm{P})$ & 2,152 & 26.53 & 0.0001 & 2,152 & 11.05 & 0.0001 & 2,152 & 29.83 & 0.0001 & 2,139 & 13.47 & 0.0001 \\
\hline Distance (D) & 1,152 & 0.31 & 0.579 & 1,152 & 1.60 & 0.210 & 1,152 & 0.04 & 0.835 & 1,139 & 0.22 & 0.640 \\
\hline Microhabitat (M) & 1,152 & 13.32 & 0.001 & 1,152 & 2.82 & 0.095 & 1,152 & 4.63 & 0.033 & 1,139 & 0.58 & 0.446 \\
\hline$P \times D$ & 2,152 & 2.62 & 0.076 & 2,152 & 1.29 & 0.279 & 2,152 & 4.13 & 0.018 & 2,139 & 1.67 & 0.193 \\
\hline $\mathrm{P} \times \mathrm{M}$ & 2,152 & 0.17 & 0.841 & 2,152 & 0.20 & 0.822 & 2,152 & 0.59 & 0.558 & 2,139 & 0.22 & 0.802 \\
\hline $\mathrm{M} \times \mathrm{D}$ & 1,152 & 0.95 & 0.331 & 1,152 & 0.86 & 0.354 & 1,152 & 0.65 & 0.422 & 1,139 & 0.08 & 0.780 \\
\hline $\mathrm{M} \times \mathrm{D} \times \mathrm{P}$ & 2,152 & 0.26 & 0.769 & 2,152 & 0.24 & 0.790 & 2,152 & 0.58 & 0.559 & 2,139 & 0.22 & 0.802 \\
\hline
\end{tabular}

Note: Shown are the effects of pericarp removal (P), distance from the mother plant (D), and microhabitat (M), as well as their second- and third-order interactions, on the percentage of seed rotting and invertebrate predation, seed germination, and percentage of seedling emergence.

to be significant for seed rotting (Table 1). Compared with rotting, predation by invertebrates accounted for only a small portion of seed mortality (Fig. 1B). Furthermore, because an estimated fraction of seeds $(2.6 \% \pm 1.3 \%, n=60 ;$ J. M. Fedriani, M. Zywiec, and M. Delibes, unpublished data) was likely to have been depredated before the experiment was set up, our measures of seed predation are probably somewhat overestimated. The percentage of invertebrate predation for seeds in partially depulped and whole fruits was fivefold and 3.4-fold higher than for clean seeds (Fig. 1B), these differences being significant (Table 1). Differences between whole and partially depulped fruits were not significant, and no other factor or interaction had a significant effect on seed predation $(P>0.095)$. Thus these results clearly show that the fruit pericarp had a detrimental effect on seed survival, mostly due to the inhibition or delaying of germination, that facilitated rotting.

Slightly over half of the sown seeds germinated during our study. Pericarp removal had a strong significant effect on germination (Table 1). As predicted, germination for seeds in partially depulped fruits was 1.5 -fold higher than for seeds in whole fruits (Fig. 1C). Consistent with these results, mean percentages of germination for clean seeds was 1.9 -fold and 1.3-fold higher than for seeds in whole and partially depulped fruits (Fig. 1C). Interestingly, however, there was a significant interaction between pericarp removal and distance from a conspecific tree, indicating that the effect of one factor was not consistent across the levels of the second factor. Specifically, tests of slices indicated that for clean seeds, germination was significantly $(P<0.05)$ higher away from than beneath conspecifics, while for partially depulped and whole fruits the trend was reversed (Fig. 1C), although these last differences were not significant $(P>0.190)$. We also found a significant effect of microhabitat (Table 1): as predicted, the percentage of germination under Pistacia $(57.2 \% \pm$ $5.2 \%)$, was higher than in open microhabitat $(49.2 \% \pm$ $5.3 \%)$.

\section{Amount and speed of seedling emergence}

The overall percentage of $P$. bourgaeana seedling emergence in our sowing was $59.7 \%$ (437 out of 732 germinated seeds). For whole and partially depulped fruits, however, many seedlings from germinated seeds were unable to emerge out of the pericarp. Indeed, large numbers of split testas were found within fruit remains in depots where no or few seedlings had emerged. Pericarp removal again had a strong significant effect on the likelihood of seedling emergence (Table 1), with the mean percentage of emergence for partially depulped fruits being 3.2 times higher than for whole fruits (Fig. 1D). Consistently, the mean percentage of emergence for clean seeds was 7.8 and 2.4 times higher than for whole and partially depulped fruits, respectively (Fig. 1D). No other factor or interaction had a significant effect on the likelihood of emergence (Table 1).

In general, seedling emergence started one month after sowing and occurred over five months (i.e., until March 2009; Fig. 2) but its speed varied across the different treatments. The Cox regression analysis indicated that, as predicted, the presence of fruit pericarp strongly delayed $P$. bourgaeana seedling emergence (Table 2, $P=0.0001$; Fig. 2). Thus on average, seedlings from cleaned seeds and partially depulped fruits emerged 2.2 and 1.1 months earlier, respectively, than those from whole fruits (Fig. 2). Seedlings from clean seeds emerged, on average, 1.2 months earlier than those from partially depulped fruits. There was also a significant effect of microhabitat (Table 2); on average, seedlings under Pistacia emerged 0.2 months earlier than those in open interspaces.

As predicted, early-emerged seedlings from depulped seeds were generally larger than those that emerged later on from whole fruits. For example, the number of leaves in seedlings emerging from completely and partially depulped seeds was $>1.5$-fold greater than for those emerging from whole fruits (Fig. 1E), a statistically significant effect $\left(F_{2,286}=6.58, P<0.002\right)$. Interestingly, when we included in a similar linear model the date of emergence as covariate $\left(F_{1,285}=19.77, P<0.0001\right)$, the 

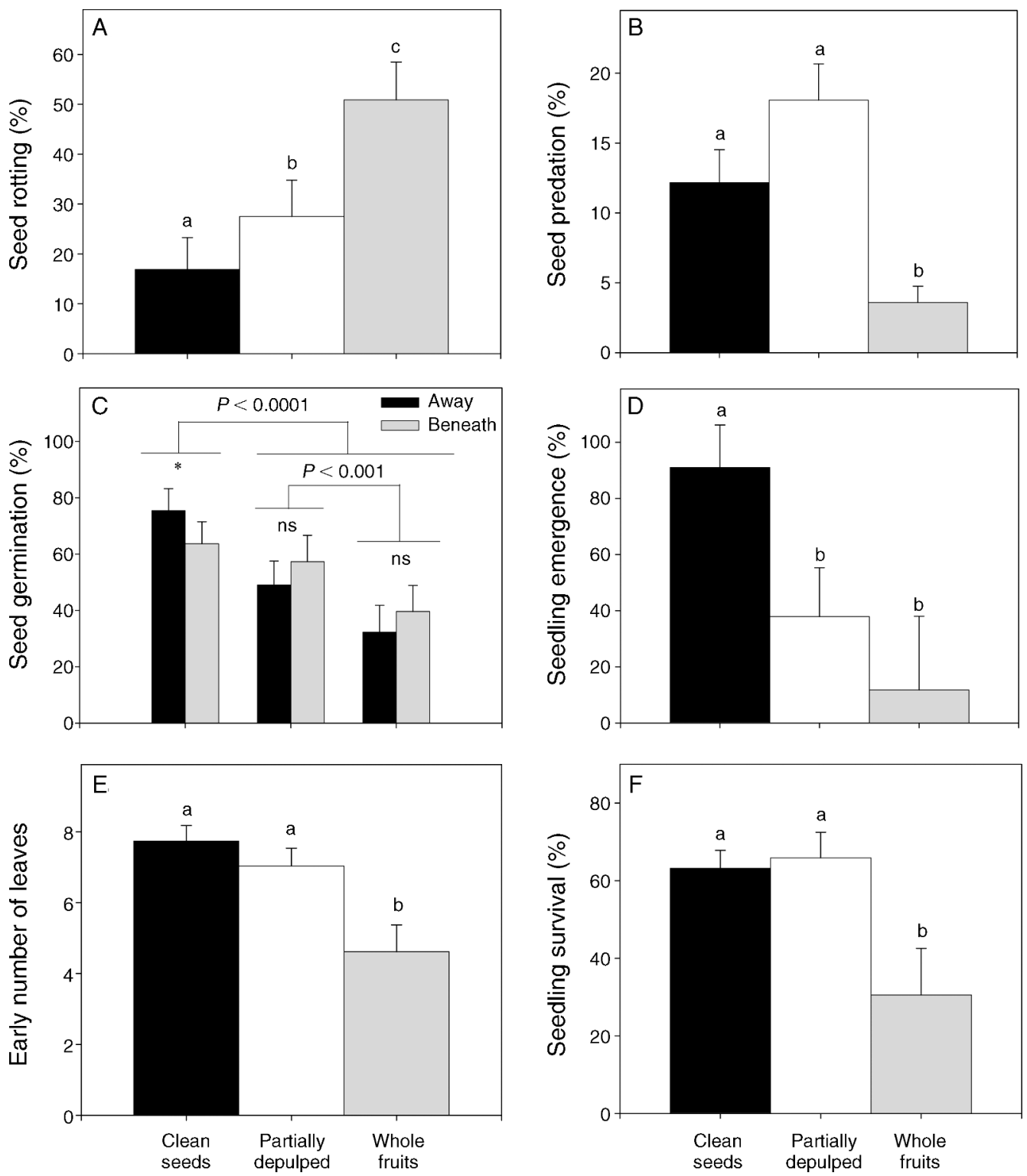

FIG. 1. Model-corrected mean percentages $( \pm$ SE) of different processes and fitness components of the Iberian pear Pyrus bourgaeana as a function of pericarp consumption in Doñana National Park, southwestern Spain. (A) Seed rotting (rotted seeds divided by total starting number of seeds). (B) Invertebrate seed predation (depredated seeds divided by total starting number of seeds). (C) Seed germination (germinated seeds divided by total starting number of seeds). Note that seed germination the interaction between pericarp consumption and distance from reproductive conspecific (i.e., beneath and away; $\sim 15 \mathrm{~m}$ from fruiting trees) was significant (Table 1); panel (C) illustrates such interaction. (D) Seedling emergence (number of germinants that emerged as seedlings divided by the number of germinated seeds). (E) Number of seedling leaves in April 2008. (F) Seedling survival to age 20 months (number of seedlings alive at the end of the study divided by the number of emerged seedlings). Within a panel, different lowercase letters among pericarp treatments denote significant $(P<0.05)$ differences. Significance in panel $(\mathrm{C})$ is indicated as: ${ }^{*} P$ $<0.05$; ns, not significant.

effect of pericarp removal on the number of leaves turned insignificant $\left(F_{2,285}=1.42, P=0.149\right)$, suggesting that the effect of pulp removal on growth was largely mediated by an advance in emergence time. Further details concerning the effect of our treatments on seedling size (i.e., height, and dry mass) are shown in Appendix B.

\section{Seedling survivorship}

Most seedlings $(90.2 \%, n=437)$ had died by the end of the study. The main identifiable causes of seedling mortality were desiccation during summer and fungal attack. The Cox regression model revealed a marginally significant effect of pericarp removal on seedling 
Open
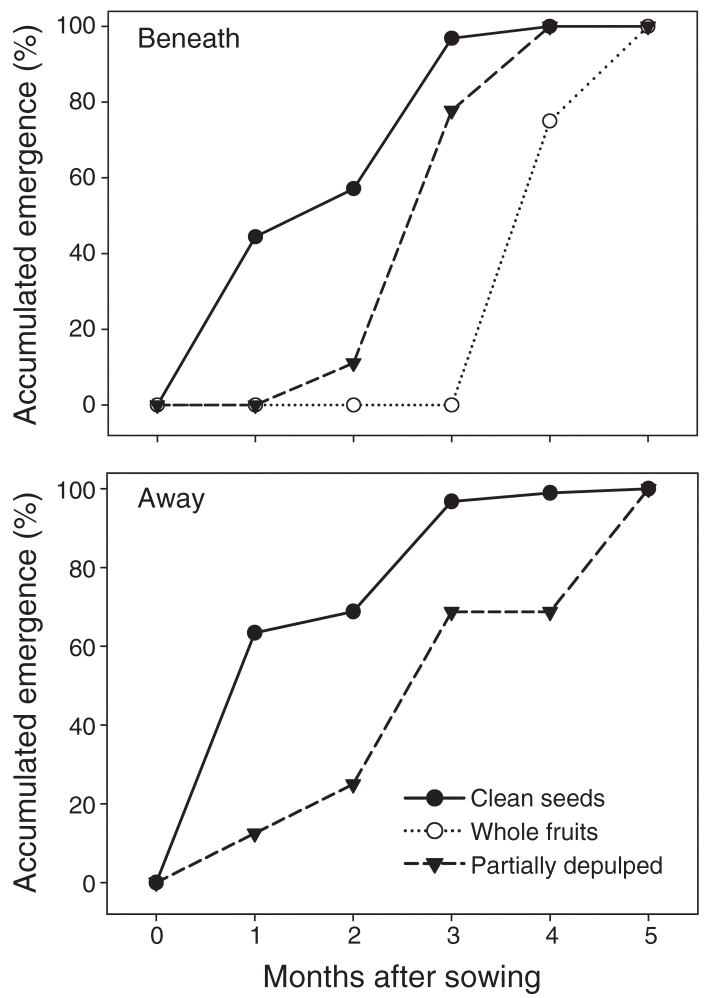

Pistacia
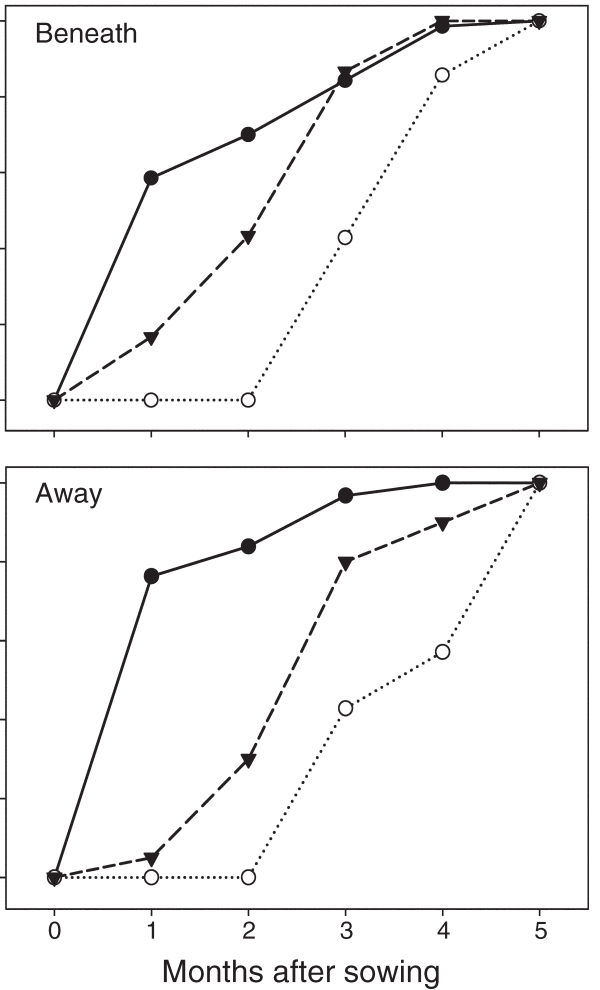

FIG. 2. Cumulative percentages of Pyrus bourgaeana seedling emergence as a function of pericarp consumption, microsite (i.e., under a Pistacia shrub or in an open microsite), and distance from reproductive conspecifics (i.e., beneath and away [ $\sim 15 \mathrm{~m}]$ from fruiting trees). Because only one seedling emerged from whole fruits away from conspecifics in the open microsite, the corresponding curve is not shown.

survivorship ( $P=0.061$; Table 2$)$. According to our expectations, the estimated relative risk of death of seedlings that emerged from whole fruits doubled that of seedlings from partially depulped fruits and cleaned seeds. Besides, the estimated relative risk of seedling death beneath conspecifics was 1.4 times higher than for seedlings emerged away from conspecifics $(P<0.01$; Table 2). No other treatment as main factor or their interactions had a significant effect on seedling survi- vorship (Table 2). Interestingly, when we included in a similar Cox model the date of seedling emergence as covariate $\left(\chi^{2}=4.80, \mathrm{df}=1, P<0.05\right)$, the effect of pericarp removal turned insignificant $\left(\chi^{2}=4.0, \mathrm{df}=2, P\right.$ $=0.135)$, indicating that the effect of pulp removal on survivorship was achievable through advancing emergence date. Because of the small number of seedlings that survived to the end of the study $(n=46)$, we did not analyze the final percentages of seedling survival.

TABLE 2. Main results of the Cox regression models ( $\chi^{2}$ values) in a study of the Iberian pear Pyrus bourgaeana in Doñana National Park, southwestern Spain.

\begin{tabular}{|c|c|c|c|c|c|c|}
\hline \multirow[b]{2}{*}{ Factor } & \multicolumn{3}{|c|}{ Speed of seedling emergence } & \multicolumn{3}{|c|}{ Seedling survivorship } \\
\hline & $\mathrm{df}$ & $\chi^{2}$ & $P$ & $\mathrm{df}$ & $\chi^{2}$ & $P$ \\
\hline Pericarp removal $(\mathrm{P})$ & 2 & 116.20 & 0.0001 & 2 & 5.60 & 0.061 \\
\hline Distance (D) & 1 & 0.20 & 0.655 & 1 & 8.0 & 0.005 \\
\hline Microhabitat (M) & 1 & 10.20 & 0.002 & 1 & 1.0 & 0.317 \\
\hline$P \times D$ & 5 & 1.40 & 0.924 & 5 & 2.0 & 0.849 \\
\hline $\mathrm{P} \times \mathrm{M}$ & 5 & 1.0 & 0.963 & 5 & 1.6 & 0.901 \\
\hline $\mathrm{M} \times \mathrm{D}$ & 3 & 0.20 & 0.978 & 3 & 0.60 & 0.439 \\
\hline $\mathrm{M} \times \mathrm{D} \times \mathrm{P}$ & 11 & 2.60 & 0.995 & & $\dagger$ & \\
\hline
\end{tabular}

Note: Shown are the effects of pericarp removal (P), distance from the mother plant (D), and microhabitat (M), as well as their second- and third-order interactions, on the speed of seedling emergence and seedling survivorship.

$\dagger$ A model including the third-order interaction did not converge. 

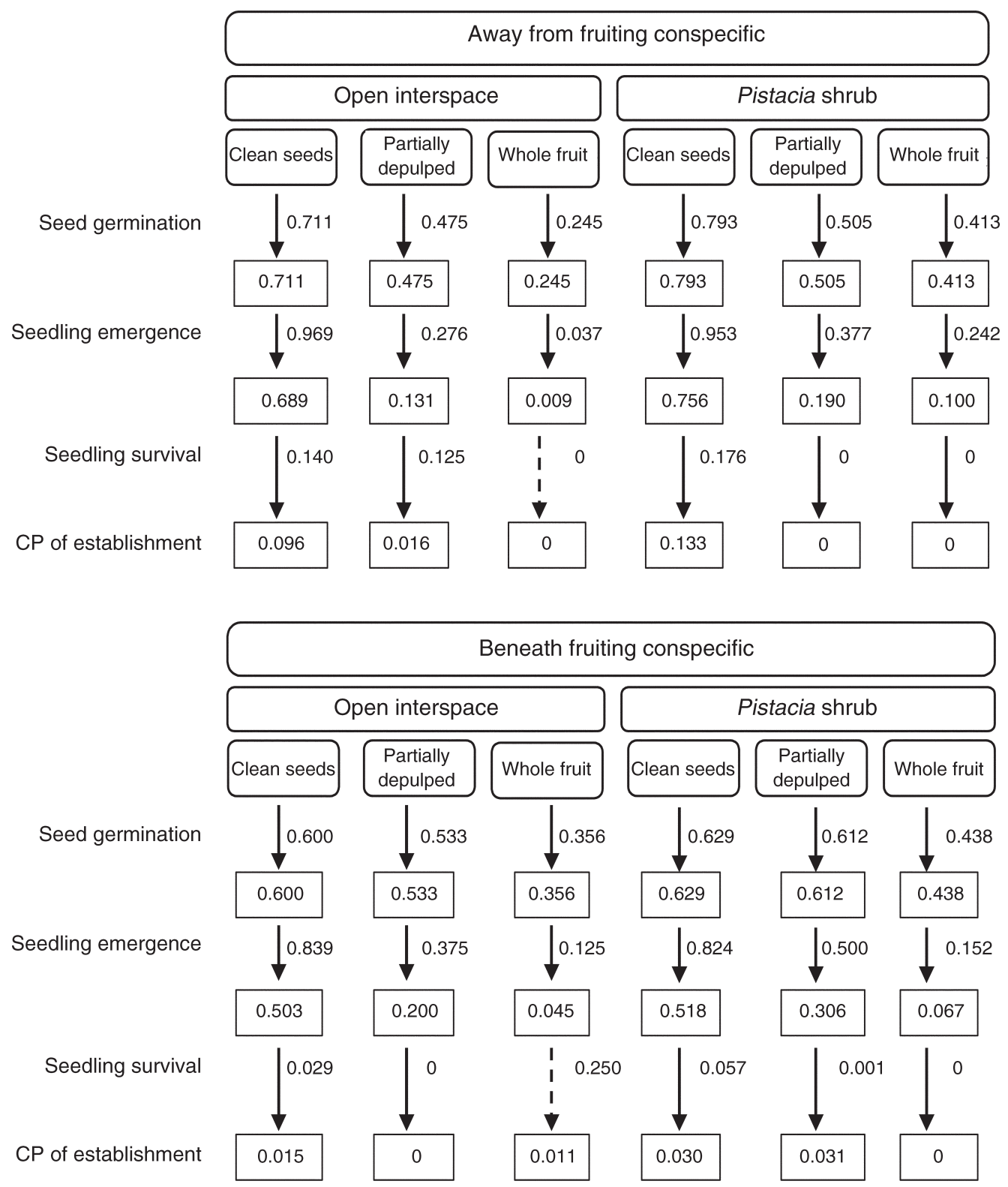

FIG. 3. Diagram of Pyrus bourgaeana propagule fate showing the proportion of seeds or seedlings moving from one stage to the next (i.e., transition probabilities [TP]; values next to the arrows) and the proportion of the initial propagules still alive at each stage (values inside the boxes). Overall cumulative probability (CP) of establishment for each treatment combination is also shown. Dashed arrows for some TPs indicate limited sample sizes.

However, a mixed model considering as experimental units the 185 seedlings that were alive at the end of April 2009 (i.e., before extensive summer mortality) showed that pericarp removal had a significant effect $\left(F_{2,416}=\right.$ 3.23, $P<0.05)$ on survival. Mean percentages of seedling survival were higher for clean and partially depulped seeds as compared with seedlings from whole fruits (Fig. 1F). When we included date of emergence as covariate $\left(F_{1,415}=3.54, P=0.060\right)$, the effect of pericarp removal on survival turned insignificant $\left(F_{2,415}=2.63, P\right.$ $=0.073$ ).

\section{Transition probabilities and overall probability of establishment}

Transition probabilities (TP) among all stages considered in this study as well as the cumulative probabilities of seedling establishment are summarized in Fig. 3. In general, seedling emergence and survival were the most critical bottlenecks of $P$. bourgaeana seedling establishment during our field experiment, though their relative importance varied among treatment combinations (Fig. 3). Specifically, for whole fruits, seedling emergence (rather than seed germination) 
was a critical stage both beneath and away from fruiting conspecifics and in both microhabitats (on average, only $14.5 \%$ of germinated seeds within whole fruits survived to reach this stage; Fig. 3). Conversely, for clean seeds, seedling survival was clearly the most critical stage both beneath and away from conspecifics and in both microhabitats, even though these seedlings showed the highest resprouting capability ( $13.2 \%$ vs. $9.4 \%$ and $8.7 \%$ for partially depulped and whole fruits, respectively). Thus on average, only $10.1 \%(n=333)$ survived to end of the study. The pattern of TPs for partially depulped fruits was intermediate between those reported; whereas under fruiting trees, seedling survival was the most limiting stage, and away from conspecifics both seedling emergence and survival were key stages (Fig. 3). Overall, the cumulative probabilities of establishment over the first 20 months (i.e., the product of all TPs) of totally $(0.068 \pm 0.028, n=4)$ and partially depulped seeds $(0.012 \pm 0.007, n=4)$ were 24.9 and 4.3 times higher, respectively, than for seeds in whole fruits $(0.003 \pm$ $0.003, n=4$; Fig. 3). Cleaned seeds had an average cumulative probability of seedling establishment 5.8 times higher than for seeds within partially depulped fruits. Thus these results show that in P. bourgaeana, removal of the persistent fruit pericarp clearly augmented the probability of seedling establishment and that the fitness benefit took place in all levels of spatial heterogeneity considered.

\section{DisCUSSION}

Our field experimental evaluation of pulp-feeder effects on tree recruitment allowed us to (1) assess the overlooked fate of seeds within partly depulped and whole fruits, (2) evaluate the critical possibility that fitness benefits of pulp consumption are offset by low survival either beneath mother plants or in adverse microhabitats, and (3) identify potential conflicting effects of pulp consumption during the course of seed germination and seedling establishment. This seldomadopted approach appeared essential to comprehend the previously unnoticed functional uniqueness of pulp feeders, which have been long considered predominately thieves or cheaters of seed-disperser mutualisms (e.g., Howe 1977, Herrera 1981, Wheelwright and Orians 1982, Snow and Snow 1988, Tewksbury et al. 2008, Olesen et al. 2010).

\section{The consistent effect of pericarp removal}

Our study clearly shows that pericarp removal had a positive effect on seed and seedling fate. For instance, seeds within whole fruits underwent much higher rotting rates than seeds within partly depulped fruits and than clean seeds. This suggests that the potential defensive role against pathogens of fruit pericarp (Cipollini and Levey 1997, Fragoso et al. 2003), if it was ever present, disappeared during the course of this study (due perhaps to the oxidation and breakdown of polyphenolic compounds; Fischer et al. 2007). Pericarp had an enduring germination inhibitory effect, with partially and completely depulped seeds showing germination rates (1.5-fold and 1.9-fold, respectively) higher than for whole ripe fruits. Contrary to what is often assumed for fleshy-fruited species (Traveset et al. 2007), however, depulpation had a stronger effect on seedling emergence than on seed germination, probably because the pericarp acted as a physical barrier that seedlings hardly passed through. Indeed, the increase in the joint probability of germination plus emergence due to pulp removal (3.9fold and 11.9-fold for partially and completely depulped seeds, respectively) was comparable to those reported in the few available field assays (e.g., 14.8-fold for Sorbus comixta [Yagihashi et al. 1998], 10.3-fold and 1.7-fold for Melicytus lanceolatus and Pennantia corymbosa, respectively [Robertson et al. 2006], $\geq 4.5$-fold for Monodora myristica [Balcomb and Chapman 2003]). Nonetheless, germination, emergence, and even seedling establishment were possible from ripe whole fruits (e.g., Balcomb and Chapman 2003), indicating that the dependence of endozoochorous plants on frugivores, though certainly strong, is not absolute.

Changes in emergence date can have important consequences for plant fitness, the magnitude and even the sign of such effects being contingent on individual species and on a myriad of biotic and abiotic factors (Seiwa 2000, Gómez 2004, Kelly et al. 2004, Verdú and Traveset 2005, De Luis et al. 2008). Our experimental results revealed that for Pyrus bourgaeana in the mediterranean conditions of Doñana, pericarp removal accelerated the timing of emergence, and this, in turn, enhanced seedling growth and also survivorship (likely because seedlings grow up sufficiently during spring to survive the harsh summer drought; Verdú and Traveset 2005). Thus as a rule, the effects of pericarp removal were additive, leading to a tree recruitment increase. In general, and especially in the case of fleshy-fruited species with high pericarp: seed mass ratios, it seems likely that pulp feeders will accelerate emergence and augment plant recruitment. Nevertheless, because this study represents the first exhaustive evaluation of pulpfeeder effects on different stages of a plant life cycle and recruitment process under field conditions, further similar studies evaluating the pervasiveness of our findings in other fruit-frugivore systems are needed (Kelly et al. 2004, Robertson et al. 2006, Traveset et al. 2007).

\section{Spatial patterns}

The pervasive positive effects of pulp removal on propagule fate did not remain unaltered by the spatial heterogeneity that characterizes real landscapes (Maestre et al. 2005, Pugnaire and Valladares 2007, Traveset et al. 2007). For instance, germination of clean seeds was higher away from than under fruiting trees, supporting that fungal pathogens, chemical allelopathy, and mechanical inhibition could be associated with fruiting P. bourgaeana trees (Fenner and Thompson 
2005). Conversely, for partially depulped and whole fruits, no significant differences were found in seed germination under than away from conspecifics. Moreover, as predicted (Maestre et al. 2005, Pugnaire and Valladares 2007), the amount and speed of seedling emergence was higher and seedling size greater (Appendix B) under Pistacia shrubs than in the open microhabitat. Therefore, the outcome of pericarp removal by frugivores seemed somewhat contingent upon spatial variations in biotic and abiotic conditions (Traveset et al. 2007, Fedriani and Delibes 2009b).

Small-sized pulp feeders frequently are labeled as thieves of seed-disperser mutualisms because they ingest the fruit reward and drop the seeds beneath parent plants, where they are thought unlikely to survive (e.g., Howe 1980, Augspurger 1984, Fragoso et al. 2003, Fenner and Thompson 2005). Unexpectedly, however, we did not find support for that assumption regarding most measured $P$. bourgaeana fitness components. Lack of distance effects is consistent with thorough metaanalyses of seed predation (Hyatt et al. 2003), results from other studies (e.g., Chapman and Chapman 1995, Cordeiro and Howe 2003), the strong spatial aggregation of $P$. bourgaeana adults in our study site (Fedriani et al. 2010), and our extensive field data of established seedlings and saplings under fruiting trees (J. M. Fedriani, M. Zywiec, and M. Delibes, unpublished data). Although seedling survival was slightly higher away from than beneath fruiting trees, pericarp removal resulted in strong fitness benefits during the examined stages (germination, emergence, seedling growth, and survival) that to age two years more than compensated for a higher seedling mortality under fruiting trees (Fig. $3)$. Thus although pulp feeders generally do not move handled seeds away from the maternal environment, they show a strong potential to raise local recruitment.

\section{Functional uniqueness of pulp feeders}

Pulp removal clearly augmented $P$. bourgaeana seedling establishment beneath fruiting conspecifics, which is likely to increase the long-term tree population persistence. Consequently, rabbits and other pulp feeders can offer an important service to this tree and should be considered mutualists. Such mutualistic function of pulp feeders is likely to occur also in many other fruit-frugivore systems. For example, small birds often eat part of the pericarp and leave the seeds within discarded fruit parts under fruiting plants (e.g., Snow and Snow 1988, Jordano and Schupp 2000). Specifically, nine bird species acting as pulp feeders comprised up to $35 \%$ and $25 \%$ of total frugivore visits and fruit removal, respectively, of fruiting Prunus mahaleb trees in southern Spain (Jordano and Schupp 2000). Nonetheless, by partially removing the rewarding pericarp, pulp feeders are likely to lessen fruit ingestion and subsequent longdistance seed dispersal by legitimate dispersers. This likely limits the tree population potential to (re)colonize vacant areas, and also has a cost at the metapopulation level (Levin et al. 2003, Spiegel and Nathan 2007, Nathan et al. 2008; but see Schupp et al. [2010]). By increasing seedling recruitment under fruiting trees, however, many small pulp feeders such as lagomorphs, small birds, and some rodents could play a rather unique ecological service differing from both long- (e.g., Jordano et al. 2007, Spiegel and Nathan 2007) and short-distance dispersal (e.g., Vander Wall et al. 2005, Beck and Vander Wall 2010).

Recent consumer-resource models (Holland and DeAngelis 2009, 2010) predict that the outcome of the interaction among frugivores and fruiting plants is often dependent on their respective population densities. Pulp feeders are likely to positively affect endozoochorous plant fitness under the increasingly pervasive scenario of lack or scarcity of medium- and large-sized frugivores due to anthropogenic activities (e.g., hunting, habitat fragmentation; Bond 1994, Corlett 2007, Holbrook and Loiselle 2009, Ozinga et al. 2009, Wotton and Kelly 2011). Thus in tropical (Corlett 2007, Holbrook and Loiselle 2009) and temperate (García et al. 2011, Wotton and Kelly 2011) habitats experiencing "selective defaunation" (sensu Dirzo and Miranda 1990), small and resilient pulp feeders could partly replace and complement the services provided by usually large and sensitive, legitimate seed dispersers. Conversely, in habitats with abundant legitimate dispersers, pulp feeders are more likely to lessen fruit ingestion and consequent longdistance seed dispersal by the former, thus inferring a negative effect at the plant metapopulation level. Interplay between theory and empirical research is clearly needed to comprehensively understand the population dynamics of such conditional plant-frugivore mutualisms (Holland and DeAngelis 2010).

To conclude, as for most species interactions (Bronstein 1994), the interaction between pulp feeders and fleshy-fruited plants is characterized by costs and benefits. Specifically, the costs of precluding longdistance dispersal must be balanced against the benefits of enhancing recruitment under conspecifics. Such costs and benefits are highly contingent on the community context (abundance of pathogens, presence of legitimate dispersers, etc.) in which these fruit-frugivore interactions are embedded. Organisms displaying concurrently cheating and honest behaviors are likely prevalent among other sort of mutualisms (Bronstein et al. 2006, Irwin et al. 2010, Kiers et al. 2010). Thus the apparent paradox of mutualism persistence in the face of exploitation could be clarified partly if, as in our study system, exploiters deny hosts with one or more services at a certain stage, while eventually supplying some subtler but critical services. We support that the persistent language of mutualists vs. thieves, cheaters, or exploiters might be misleading (Palmer et al. 2010).

\section{ACKNOWLEDGMENTS}

We are indebted to Gemma Calvo and innumerable volunteers for their valuable field and lab assistance. We thank Steve Vander Wall, Alastair Robertson, William F. Morris, 
Andrea Loayza, and two anonymous reviewers for thoughtful comments on earlier versions of the manuscript. Pedro Jordano, Jordi Bascompte, Judie Bronstein, Nat Holland, Arnt Hampe, and Xavi Picó provided ideas and helpful discussion. The Spanish Ministerio de Medio Ambiente (National Park Service, grant 070/2009) and Ministerio de Educación y Ciencia (CGL2007-63488/BOS and CGL2010-21926/BOS) supported this study.

\section{Literature Cited}

Alcántara, J. M., and P. J. Rey. 2003. Conflicting selection pressures on seed size: evolutionary ecology of fruit size in a bird-dispersed tree, Olea europaea. Journal of Evolutionary Biology 16:1168-1176.

Aldasoro, J. J., C. Aedo, and F. Muñoz-Garmendia. 1996. The genus Pyrus L. (Rosaceae) in south-west Europe and North Africa. Biological Journal of Linnean Society 121:143-158.

Augspurger, C. K. 1984. Seedling survival of tropical tree species: interactions of dispersal distance, light-gaps, and pathogens. Ecology 65:1705-1712.

Balcomb, S. R., and C. A. Chapman. 2003. Bridging the gap: influence of seed deposition on seedling recruitment in a primate-tree interaction. Ecological Monographs 73:625642.

Bond, W. J. 1994. Do mutualisms matter? Assessing the impact of pollinator and disperser disruption on plant extinction. Philosophical Transactions of the Royal Society B 344:83-90.

Bronstein, J. L. 1994. Conditional outcomes of mutualistic interactions. Trends in Ecology and Evolution 9:214-217.

Bronstein, J. L. 2001. The exploitation of mutualisms. Ecology Letters 4:277-287.

Bronstein, J. L., R. Alarcon, and M. Geber. 2006. The evolution of plant-insect mutualisms. New Phytologist 172:412-428.

Chapman, C. A., and L. J. Chapman. 1995. Survival without dispersers: seedling recruitment under parents. Conservation Biology 9:675-678.

Cipollini, M. L., and D. J. Levey. 1997. Secondary metabolites of fleshy vertebrate-dispersed fruits: adaptive hypotheses and implications for seed dispersal. American Naturalist 150:346-372.

Cordeiro, N. J., and H. F. Howe. 2003. Forest fragmentation severs mutualism between seed dispersers and an endemic African tree. Proceedings of the National Academy of Sciences USA 100:14052-14056.

Corlett, R. T. 2007. Pollination or seed dispersal: which should we worry about most? Pages 525-544 in A. J. Dennis, E. W. Schupp, R. J. Green, and D. W. Westcott, editors. Seed dispersal: theory and its application in a changing world. CABI Publishing, Wallingford, UK.

Curran, L. M., and C. O. Webb. 2000. Spatio-temporal scale of seed predation in mast-fruiting Dipterocarpaceae: experimental studies of regional seed availability. Ecological Monographs 70:129-148.

Daws, M. I., N. C. Garwood, and H. W. Pritchard. 2005. Traits of recalcitrant seeds in a semi-deciduous tropical forest in Panama: some ecological implications. Functional Ecology 19:874-885.

De Luis, M., M. Verdú, and J. Raventos. 2008. Early to rise makes a plant healthy, wealthy, and wise. Ecology 89:30613071.

Dennis, A. J., E. W. Schupp, R. J. Green, and D. W. Westcott. 2007. Seed dispersal: theory and its application in a changing world. CABI Publishing, Wallingford, UK.

Dirzo, R., and A. Miranda. 1990. Contemporary neotropical defaunation and forest structure, function and diversity: a sequel to John Terborgh. Conservation Biology 4:444-447.

Eisler, R. 1991. Cyanide hazards to fish, wildlife, and invertebrates: a synoptic review. U.S. Fish and Wildlife Service, Biological Report 85.
Fedriani, J. M., and M. Delibes. 2009a. Seed dispersal in the Iberian pear Pyrus bourgaeana: a role for infrequent mutualists. Ecoscience 16:211-221.

Fedriani, J. M., and M. Delibes. 2009b. Functional diversity in fruit-frugivore interactions: a field experiment with Mediterranean mammals. Ecography 32:983-992.

Fedriani, J. M., and M. Delibes. 2011. Dangerous liaisons disperse the Mediterranean dwarf palm: fleshy-pulp defensive role against seed predators. Ecology 92:304-315.

Fedriani, J. M., T. Wiegand, and M. Delibes. 2010. Spatial patterns of adult trees and the mammal-generated seed rain in the Iberian pear. Ecography 33:545-555.

Fenner, M., and K. Thompson. 2005. The ecology of seeds. Cambridge University Press, Cambridge, UK.

Fischer, T. C., C. Gosch, J. Pfeiffer, H. Halbwirth, C. Halle, K. Stich, and G. Forkmann. 2007. Flavonoid genes of pear (Pyrus communis). Trees 21:521-529.

Fragoso, J. M. V., K. M. Silvius, and J. A. Correa. 2003. Longdistance seed dispersal by tapirs increases seed survival and aggregates tropical trees. Ecology 84:1998-2006.

García, D., R. Zamora, and G. C. Amico. 2011. The spatial scale of plant-animal interactions: effects of resource availability and habitat structure. Ecological Monographs 81:103-121.

Gómez, J. M. 2004. Bigger is not always better: conflicting selective pressures on seed size in Quercus ilex. Evolution 58:71-80.

Herrera, C. M. 1981. Are tropical fruits more rewarding than temperate ones? American Naturalist 118:896-907.

Herrera, C. M. 2009. Multiplicity in unity. Plant subindividual variation and interactions with animals. University of Chicago Press, Chicago, Illinois, USA.

Holbrook, K. M., and B. A. Loiselle. 2009. Dispersal in a neotropical tree, Virola flexuosa (Myristicaceae): does hunting of large vertebrates limit seed removal? Ecology 90:14491455.

Holland, J. N., and D. L. DeAngelis. 2009. Consumer-resource theory predicts dynamic transitions between outcomes of interspecific interactions. Ecology Letters 12:1357-1366.

Holland, J. N., and D. L. DeAngelis. 2010. A consumerresource approach to the density-dependent population dynamics of mutualism. Ecology 91:1286-1295.

Howe, H. F. 1977. Bird activity and seed dispersal of a tropical wet forest tree. Ecology 58:539-550.

Howe, H. F. 1980. Monkey dispersal and waste of neotropical fruit. Ecology 105:944-959.

Hyatt, L. A., M. S. Rosenberg, T. G. Howard, G. Bole, W. Fang, J. Anastasia, and K. Brown. 2003. The distance dependence prediction of the Janzen-Connell hypothesis: a meta-analysis. Oikos 103:590-602.

Irwin, R. E., J. L. Bronstein, J. S. Manson, and L. Richardson. 2010. Nectar Robbing: Ecological and Evolutionary Perspectives. Annual Review of Ecology, Evolution and Systematics 41:271-292.

Jordano, P. 1995. Angiosperm fleshy fruits and seed dispersers: a comparative analysis of adaptation and constraints in plant-animal interactions. American Naturalist 145:163-191.

Jordano, P., P. M. Forget, J. E. Lambert, K. Böhning-Gaese, A. Traveset, and S. J. Wright. 2010. Frugivores and seed dispersal: mechanisms and consequences for biodiversity of a key ecological interaction. Biology Letters 7:321-323.

Jordano, P., C. García, J. A. Godoy, and J. L. García-Castaño. 2007. Differential contribution of frugivores to complex seed dispersal patterns. Proceedings of the National Academy of Sciences USA 104:3278-3282.

Jordano, P., and E. W. Schupp. 2000. Seed dispersal effectiveness: the quantity component and patterns of seed rain for Prunus mahaleb. Ecological Monographs 70:591615.

Kelly, D., J. J. Ladley, and A. W. Robertson. 2004. Is dispersal easier than pollination? Two tests in New Zealand Loranthaceae. New Zealand Journal of Botany 42:89-103. 
Kiers, E. T., T. M. Palmer, A. R. Ives, J. F. Bruno, and J. L. Bronstein. 2010. Mutualisms in a changing world: an evolutionary perspective. Ecology Letters 13:1459-1474.

Levey, D. J., W. R. Silva, and M. Galetti. 2002. Seed dispersal and frugivory. CABI Publishing, Wallingford, UK.

Levin, S. A., H. C. Muller-Landau, R. Nathan, and J. Chave. 2003. The ecology and evolution of seed dispersal: a theoretical perspective. Annual Review of Ecology Systematics 34:575-604.

Littell, R. C., G. A. Milliken, W. W. Stroup, R. D. Wolfinger, and O. Schabenberger. 2006. SAS for mixed models. SAS Institute, Cary, North Carolina, USA.

Loayza, A. P., and T. Knight. 2010. Seed dispersal by pulp consumers, not "legitimate" seed dispersers, increases Guettarda viburnoides population growth. Ecology 91:2684-2695.

Maestre, F. T., F. Valladares, and J. F. Reynolds. 2005. Is the change of plant-plant interactions with abiotic stress predictable? A meta-analysis of field results in arid environments. Journal of Ecology 93:748-757.

Maloof, J. E., and D. W. Inouye. 2000. Are nectar robbers cheaters or mutualists? Ecology 81:2651-2661.

Nathan, R., F. M. Schurr, O. Spiegel, O. Steinitz, A. Trakhtenbrot, and A. Tsoar. 2008. Mechanisms of longdistance seed dispersal. Trends in Ecology and Evolution 23:638-647.

Olesen, J. M., J. Bascompte, Y. L. Dupont, H. Helberling, C. Rasmussen, and P. Jordano. 2010. Missing and forbidden links in mutualistic networks. Proceedings of the Royal Society of London 278:725-732.

Ozinga, W. A., et al. 2009. Dispersal failure contributes to plant losses in NW Europe. Ecology Letters 12:66-74.

Palmer, T. M., D. F. Doak, M. L. Stanton, J. L. Bronstein, E. T. Kiers, T. P. Young, J. R. Goheen, and R. M. Pringle. 2010. Synergy of multiple partners, including freeloaders, increases host fitness in a multispecies mutualism. Proceedings of the National Academy of Sciences USA. 107:1723417239.

Pugnaire, F. I., and F. Valladares. 2007. Functional plant ecology. Second edition. CRC Press, Boca Raton, Florida, USA.

Revilla, E., F. Palomares, and M. Delibes. 2001. Edge-core effects and the effectiveness of traditional reserves in conservation: Eurasian badgers in Doñana National Park. Conservation Biology 15:148-158.

Rey, P. J., and J. M. Alcántara. 2000. Recruitment dynamics of a fleshy-fruited plant (Olea europaea): connecting patterns of seed dispersal to seedling establishment. Journal of Ecology 88:622-633.

Robertson, A. W., A. Trass, J. J. Ladley, and D. Kelly. 2006. Assessing the benefits of frugivory for seed germination: the importance of deinhibition effect. Functional Ecology 20:5866.

Samuels, I. A., and D. J. Levey. 2005. Effects of gut passage on seed germination: do experiments answer the question they ask? Functional Ecology 19:365-368.

Santamaría, L., I. Charalambidou, J. Figuerola, and A. J. Green. 2002. Effect of passage through duck gut on germination of fennel pondweed seeds. Archives für Hydrobiology 156:11-22.

Schupp, E. W., P. Jordano, and J. M. Gómez. 2010. Seed dispersal effectiveness revisited: a conceptual review. New Phytologist 188:333-353.

Seiwa, K. 2000. Effects of seed size and emergence time on tree seedling establishment: importance of developmental constraints. Oecologia 123:208-215.

Silvius, K. M., and J. M. V. Fragoso. 2002. Pulp handling by vertebrate seed dispersers increases palm seed predation by bruchid beetles in the northern Amazon. Journal of Ecology 90:1024-1032.

Snow, B. K., and D. W. Snow. 1988. Birds and berries: a study of an ecological interaction. Poyser, London, UK.

Spiegel, O., and R. Nathan. 2007. Incorporating dispersal distance into the disperser effectiveness framework: frugivorous birds provide complementary dispersal to plants in patchy environments. Ecology Letters 10:718-728.

Tewksbury, J. J., D. J. Levey, M. Huizinga, and A. Traveset. 2008. Ecology of a spice: capsaicin in wild chilies mediates seed retention, dispersal, and germination. Ecology 89:107117.

Therneau, T. M., and P. M. Grambsch. 2000. Modeling survival data: extending the Cox model. Springer, New York, New York, USA.

Thompson, J. N. 2005. The geographic mosaic of coevolution. Chicago. University of Chicago Press, Chicago, Illinois, USA.

Traveset, A. 1994. Influence of quality of bird frugivory on the fitness of Pistacia terebinthus L. Evolutionary Ecology 8:618627.

Traveset, A., A. Robertson, and J. Rodríguez-Pérez. 2007. A review of the role of endozoochory on seed germination. Pages 79-103 in A. J. Dennis, E. W. Schupp, R. J. Green, and D. W. Westcott, editors. Seed dispersal: theory and its application in a changing world. CABI Publishing, Wallingford, UK.

Vander Wall, S. B., K. M. Kuhn, and M. J. Beck. 2005. Seed removal, seed predation, and secondary dispersal. Ecology 86:801-806.

Verdú, M., and A. Traveset. 2005. Early emergence enhances plant fitness: a phylogenetically controlled meta-analysis. Ecology 86:1385-1394.

Vilà, M., I. Bartomeus, I. Gimeno, A. Traveset, and E. Moragues. 2006. Demography of the invasive geophyte Oxalis pes-caprae across a Mediterranean island. Annals of Botany 97:1055-1062.

Wheelwright, N. T., and G. H. Orians. 1982. Seed dispersal by animals: contrasts with pollen dispersal, problems of terminology, and constraints on coevolution. American Naturalist 119:402-413.

Wotton, D. M., and D. Kelly. 2011. Frugivore loss limits recruitment of large-seeded trees. Proceedings of the Royal Society B. [doi:10.1098/rspb.2011.0185]

Yagihashi, T., M. Hayashida, and T. Miyamoto. 1998. Effects of bird ingestion on seed germination of Sorbus commixta. Oecologia 114:209-212.

Yu, D. W. 2001. Parasites of mutualisms. Biological Journal of the Linnean Society 72:529-546.

\title{
Supplemental Material
}

\author{
Appendix A \\ Pictures of our study system in Doñana National Park (southwest Spain) (Ecological Archives E093-051-A1).
}

\section{Appendix B}

Additional analyses and details concerning the effects of pericarp removal, distance from fruiting conspecifics, and microhabitat on Pyrus bourgaeana seedling size (Ecological Archives E093-051-A2). 